\title{
Physical and Performance Changes in Rugby Union Female Student-Athletes Over 31-and 52- Weeks
}

\author{
By Neetu Rishiraj ${ }^{*}$ \\ Brian Niven ${ }^{\dagger}$
}

\begin{abstract}
Only two papers have been published on physical and/or performance characteristics for women Rugby Union (RU) players and no data is available for Academy/ developing women $R U$ student-athletes. The objective of this paper was to investigate, using descriptive statistics, the potential enhancement of physical and performance variables of New Zealand Women RU Academy student-athletes (NZWRUSA) over a 31-weekpremier league season and over 52-weeks, and compare this data with previous publications. Players trained 25hours per week, with an additional 12 to 15hours being scheduled for team practices and game play. Data collection was scheduled for set intervals. Over the Otago Rugby Football Union premier league season (weeks 1-31) mean data illustrated an increase in body weight(trivial Cohn's effect size (ES/d)) with concurrent performance enhancement in all but one performance variable, ES ranging between trivial $(d=0.08)$ and large $(d=2.44)$. Over 52-weeks of training, body weight increase was again accompanied with improvements in all performance parameters except the two sprints, with large ES difference in lower extremity power $(d=1.49)$, upper body strength-bench press $(d=1.44)$, and anaerobic endurance effort $(d=2.37)$. Physical and performance enhancement, over a 31-week competitive-season and over 52-weeks, is possible even with an increase in body weight.
\end{abstract}

Keywords: Female student-athletes, performance, Rugby Union.

\section{Introduction}

Rugby Union (RU) is a high-intensity collision team sport and since 1871, rugby union (RU), men's 15-a-side, has had a long and distinguished history including being recognized as a Summer Olympic Games medal sport. Men's RU joined the professional ranks in 1995 and is now played professionally in Argentina, France, Japan, Oceanic regions, South African, United Kingdom, and the USA. Women RU athletes continue to play at the sub-elite (provincial/state teams) and elite (International Rugby Board [IRB] Women's Rugby World Cup) levels; moreover, female RU players have retained amateur status.

RU players possess a wide range of physical and physiological qualities which include acceleration, agility, aerobic and anaerobic fitness, power, speed, and strength as intense periods of rucking, sprinting, and tackling actions are continually required, separated by short bouts of recovery. Since the male athletes

${ }^{*}$ Director, ACTIN Health \& Rehabilitation Inc., Vancouver, BC, Canada.

${ }^{\dagger}$ Senior Lecturer, Department of Mathematics \& Statistics, University of Otago, Dunedin, New Zealand. 
gained professional status, regardless of the gender, the physical and physiological demands of the game have increased. Specifically, there are a greater number of collisions, passes, rucks, tackles, tries, and ball-in-play time/work-rest ratio(Cahill et al. 2013). To overcome these physical and physiological RU game demands, prevent injury, allow the possibility of advancing to the respective elite level of play, and to enhance career longevity, RU players must start at a young age to adapt their physical stature and metabolic systems; training programs must be designed for RU athletes to develop aerobic and anaerobic metabolic pathways with concurrent enhancement of power and strength.

In considering available research from other football (rugby league and North American Football) classifications involving male athletes, there seems to be disagreement regarding maintaining and/or improving performance levels during the off season, pre-season and throughout a competitive season. Publications on amateur male junior rugby league (RL) players reported that they were able to maintain lower-body muscular power throughout a competitive- season, while non-elite, senior club-level RL players had decreases in lower-body power (Gabbett 2005). Another study found bench press strength increased in male college-aged RL players, but plateaued in professional RL players during a competitive-season; while lower-body power was maintained in both groups(Baker 2001).Publications on North American Football players have reported significant decreases in upperbody strength and lower-body power during a competitive-season (Hrysomallis 2010), while another study reported no significant change in upper body strength (Hoffman and Kang 2003).

While the above research provides information of the possible performance changes in male athletes participating in various codes of football (rugby and North American Football),even after completion of five IRB Women's Rugby World Cups (1998 to 2014),there are only two publications on the physical and performance adaptations experienced by women RU players; one involving players participating at the elite level (Hene and Bassett 2013) and the second at the sub-elite level (Quarrie et al. 1995).The purpose of this research was to investigate physical and performance changes in New Zealand women RU Academy student-athletes (NZWRUSA) over a competitive-season (weeks 1 to 31 ) and over 52 weeks, and, where possible, to compare these data with published data.

\section{Methodology}

\section{Experimental Design}

New Zealand Women's Rugby Union (NZWRU) selected five studentathletes (two forwards and three backs) from the South Island-based Otago Rugby Football Union (ORFU) to the Black Fern World Cup training team. Two players (one forward and one back) experienced traumatic season ending injures while representing the Black Fern squad in an international test match; the remaining players were selected to the New Zealand Black Ferns team who won the 
respective IRB Women's Rugby World Cup. Ethics approval was obtained from the institutional Ethics Committee and written informed consent was received from each ORFU student-athlete. To address any potential medical concern(s), after receiving the respective player's consent, injury history and medical information was reviewed with the respective player and the ORFU Academy Manager.

\section{Experimental Procedure}

All NZWRUSAwere actively participating on an ORFU premier division team and the Black Fern team program. The student-athletes trained up to 25 hours per week with an additional 12 to 15 hours being scheduled for their respective team practices and game play (Table 1). Testing sessions were scheduled for week 1-season-start, week 31-competitive-season, and after the off-season, week 53 to ensure physical and performance data were collected from the maximum number of NZWRUSA.All anaerobic capacity and sprint testing was completed on an indoor Balsam ProBounce sand filled synthetic carpet surface. Body mass data collected using a calibrated electronic scale (A \& D Engineering Inc.).

Table 1. New Zealand Women Academy Student Athlete Weekly Game, Practice, and Training Schedule Over the Competitive Season, Weeks 1 to 31

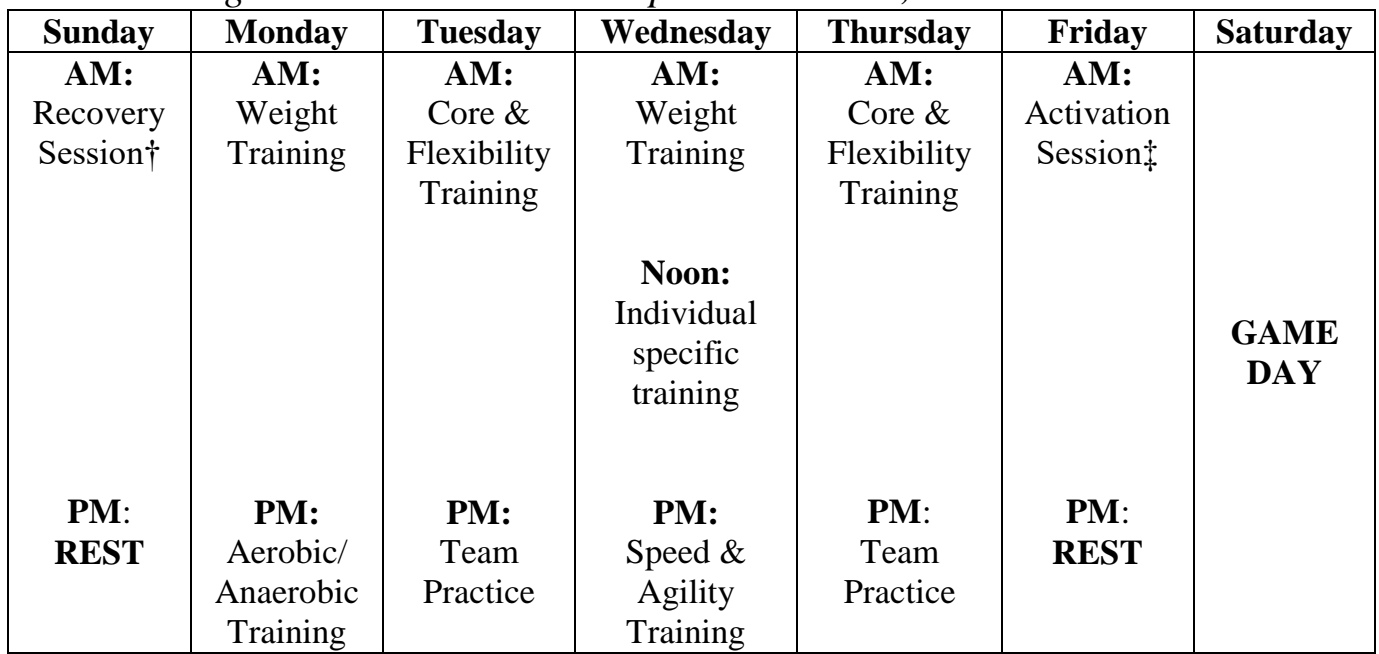

$\dagger$ Recovery session consisted of aerobic, flexibility, and massage (latter, budget dependant) followed by a team brunch.

\$Activation session involved aerobic and flexibility activities for 30-45 minutes duration.

\section{Performance Tests Completed}

All subjects performed five standardized performance tests, with data collected on nine performance variables. The respective performance tests, testing procedures, and the documented test reliability for each test are listed below.

Lower-body power - vertical jump: The subjects first stood erect, their feet flat on the floor and hips perpendicular to the Vertec (Sports Imports, OH, USA) 
vertical jump testing apparatus and with their dominant hand determined their static vertical reach. Without moving their feet prior to the jump, subjects bent their knees, jumped and touched, again with the dominant hand, the highest point on the Vertec. The distance between the static vertical reach point and the peak jump height was used to determine the maximal vertical jump in centimetres. Subjects performed three trials with a one-minute rest between trials. The coefficient of variance $(\mathrm{CV}) /$ reliability has been documented to be $5.3 \%$ (Hendrick and Anderson 1996, Moir et al. 2004).

Acceleration and speed $-5 \mathrm{~m}, 10 \mathrm{~m}$, and $40 \mathrm{~m}$ : The timed run commenced from a standing start and subjects sprinted through the $5 \mathrm{~m}, 10 \mathrm{~m}$, and $40 \mathrm{~m}$ timing gates. Sprint elapsed time (seconds) was recorded using electronic gates, (Brower Training System, Draper, UT, USA) set at a height of $75 \mathrm{~cm}$. Subjects performed three trials with a one-minute rest between trials. The CV under similar protocols has been shown to be 1.9-2.0\% (Glaister et al. 2007, Moir et al. 2004).

Upper-body strength - bench press: Using Olympic equipment, subjects performed the test with their feet flat on the floor and the buttocks/lower back remained in contact with the bench throughout the lift. A shoulder width grip was used during the lift. The bar was lowered to the chest (elbows flexed to $90^{\circ}$ and not bouncing off the chest) and returned to the start position; elbows fully extended but not locked. A series of maximal lift attempts were performed until a final 1RM was completed; data was recorded as 1RM in kilograms. The CV has been established to be $1.5 \%$ (Coutts et al. 2007, McCurdy et al. 2008).

Upper-body strength- bench pull: Again, using Olympic equipment, with the athlete lying prone on a bench, chin in contact with the bench, the athlete pulled the barbell upwards until it reached the underside of the bench. A series of maximal lift attempts were performed until a final 1RM was successful; data was recorded as 1RM in kilograms. A similar test reported a CV of 2.3\% (Anthony 2003, Seo et al. 2012).

Anaerobic endurance - Phosphate Decrement Test (PDT): Subjects performed 10 x 40m sprints, every 30 seconds. Sprint elapsed times were recorded in seconds using electronic gates (Brower Training System) after each $40 \mathrm{~m}$ sprint. A comparable repeat sprint evaluation reported a CV of 1.9\% (Bishop and Edge 2006, Bishop et al. 2001, Glaister et al. 2007).Subjects performed the PDT once (10 x 40 sprints). Data was expressed as:

- (5A) Mean PDT being the average of all $10 \times 40 \mathrm{~m}$ sprint repeats.

- (5B) Percent Fatigue provided data on the fatigue rate or performance 'drop-off' over the total $400 \mathrm{~m}$ (10 x $40 \mathrm{~m}$ sprint) distance.

- (5C) Percent Effort was obtained by comparing the Fastest PDT Sprint Repeat time with the Fastest $40 \mathrm{~m}$ Acceleration-Speed result during the 10 $\mathrm{x} 40 \mathrm{~m}$ sprint repeats.

Anaerobic capacity test (1500 m run on an outdoor rubberized $400 \mathrm{~m}$ track) was also scheduled, however poor weather conditions prevented data collection. 
Statistical Analysis

Due to the small sample size, analysis of the changes in body weight and performance levels of the student-athletes over periods of 31 and 52 weeks were completed using descriptive statistics(SPSS for Windows version 13.0 (SPSS Inc, Ill, USA)).Also, the magnitude of the differences between the means (weeks 1 31 and weeks 1 - 52) was described using Cohen's effect sizes (d/ES) with the following corresponding descriptors: trivial $=0-0.19$, small $=0.20-0.49$, medium $=0.50-0.79$, and large $>0.80($ Cohen 1992) .

\section{Results}

The age range of the three NZWRUSA was 19 to 22 years and the mean body weight was $80.7 \pm 16.9 \mathrm{~kg}$. Body weight increased by $1.4 \%(\mathrm{~d}=$ trivial $)$ between weeks 1 and 31. Atrivial decrease in body weight (1.8\%) was noted over 52weeks (Table 2).

Over the competitive season (weeks 1 to 31 ), performance improvements (ranging from $0.7 \%$ to $36 \%$ and ES ranging between trivial to large) were noted for all variables except for upper body strength - bench pull, where a $-2.7 \%$ decrease was recorded (Table 2). After 52-weeks, $1.7 \%$ to $31.9 \%$ performance improvements $(\mathrm{d}=$ small to large $)$ occurred in all variables; the 10-and the 40 meter sprint results were slower, $1.1 \%, \mathrm{~d}=$ trivial and $2.3 \%, \mathrm{~d}=$ small, respectively (Table 2). 
Table 2. New Zealand Women Academy Student-Athlete Physical and Performance Data Over 52-Week \& Comparable Data

\begin{tabular}{|c|c|c|c|c|c|c|c|c|}
\hline \multirow{2}{*}{ Body weight (kg) } & \multirow{2}{*}{$\begin{array}{c}\text { Mean } \pm \text { SD } \\
(\% \text { Change })^{*}\end{array}$} & \multicolumn{2}{|c|}{ Range } & \multicolumn{2}{|c|}{$95 \% \mathrm{CI}$} & \multirow{2}{*}{$\begin{array}{c}\text { Cohen Effect Size } \\
\& \text { (Descriptor) } \dagger\end{array}$} & \multirow{2}{*}{$\begin{array}{l}\text { ORFU Club Sr. } \\
\text { Women } \leftarrow\end{array}$} & \multirow{2}{*}{$\begin{array}{c}\text { South Africa } \\
\text { RU§ }\end{array}$} \\
\hline & & Min & Max & Lower & Upper & & & \\
\hline $\begin{array}{c}\text { Week } 1 \\
\text { (season-start) March } \\
\end{array}$ & $80.7 \pm 6.9$ & 64.0 & 98.4 & 38.6 & 123.0 & \multirow{2}{*}{$\begin{array}{c}0.08 \\
\text { (Trivial) }\end{array}$} & 68.5 & $70.2 \pm 9.9$ \\
\hline $\begin{array}{c}\text { Week 31 } \\
\text { (pre-playoffs) October }\end{array}$ & $\begin{array}{c}81.9 \pm 19.5 \\
(1.4) \\
\end{array}$ & 64.9 & 103.3 & 33.3 & 130.5 & & & $\begin{array}{c}70.7 \pm 8.8 \\
(0.7)\end{array}$ \\
\hline $\begin{array}{c}\text { Week } 53 \\
\text { (season-start) March }\end{array}$ & $\begin{array}{c}79.3 \pm 19.0 \\
(-1.8)\end{array}$ & 60.5 & 98.5 & 32.1 & 126.5 & $\begin{array}{c}0.10 \\
\text { (Trivial) }\end{array}$ & & \\
\hline \multicolumn{9}{|l|}{$\begin{array}{l}\text { Vertical Jump / Counter } \\
\text { Movement Jump }(\mathrm{cm})\end{array}$} \\
\hline $\begin{array}{c}\text { Week 1 } \\
\text { (season-start) March } \\
\end{array}$ & $36.0 \pm 2.0$ & 34.0 & 38.0 & 31.0 & 40.9 & \multirow{2}{*}{$\begin{array}{c}2.00 \\
\text { (Large) }\end{array}$} & 42.2 & $40.8 \pm 5.2$ \\
\hline $\begin{array}{c}\text { Week 31 } \\
\text { (pre-playoffs) October }\end{array}$ & $\begin{array}{c}40.0 \pm 2.0 \\
(11.1) \\
\end{array}$ & 38.0 & 42.0 & 35.0 & 44.9 & & & $\begin{array}{c}43.3 \pm 4.5 \\
(5.9) \\
\end{array}$ \\
\hline $\begin{array}{c}\text { Week } 53 \\
\text { (season-start) March } \\
\end{array}$ & $\begin{array}{c}40.7 \pm 4.0 \\
(13.0) \\
\end{array}$ & 37.0 & 45.0 & 30.6 & 50.7 & $\begin{array}{c}1.49 \\
(\text { Large })\end{array}$ & & \\
\hline \multicolumn{9}{|l|}{ 5-Meter Sprint (s) } \\
\hline $\begin{array}{c}\text { Week 1 } \\
\text { (season-start) March }\end{array}$ & $1.16 \pm 0.04$ & 1.12 & 1.20 & 1.06 & 1.25 & \multirow{2}{*}{$\begin{array}{c}1.37 \\
\text { (Large) }\end{array}$} & & \\
\hline $\begin{array}{c}\text { Week 31 } \\
\text { (pre-playoffs) October }\end{array}$ & $\begin{array}{c}1.09 \pm 0.06 \\
(-6.0)\end{array}$ & 1.03 & 1.15 & 0.94 & 1.24 & & & \\
\hline $\begin{array}{c}\text { Week } 53 \\
\text { (season-start) March }\end{array}$ & $\begin{array}{c}1.14 \pm 0.08 \\
(-1.7)\end{array}$ & 1.04 & 1.19 & 0.92 & 1.35 & $\begin{array}{c}0.32 \\
(\text { Small })\end{array}$ & & \\
\hline \multicolumn{9}{|l|}{ 10-Meter Sprint (s) } \\
\hline $\begin{array}{c}\text { Week 1 } \\
\text { (season-start) March }\end{array}$ & $1.97 \pm 0.70$ & 1.90 & 2.04 & 1.79 & 2.14 & \multirow{2}{*}{$\begin{array}{c}0.08 \\
\text { (Trivial) }\end{array}$} & & $1.98 \pm 0.11$ \\
\hline $\begin{array}{c}\text { Week } 31 \\
\text { (pre-playoffs) October }\end{array}$ & $\begin{array}{c}1.93 \pm 0.11 \\
(-2.2)\end{array}$ & 1.80 & 2.01 & 1.65 & 2.21 & & & $\begin{array}{c}1.95 \pm 0.97 \\
(-1.5)\end{array}$ \\
\hline $\begin{array}{c}\text { Week } 53 \\
\text { (season-start) March } \\
\end{array}$ & $\begin{array}{c}1.99 \pm 0.16 \\
(1.1)\end{array}$ & 1.81 & 2.12 & 1.59 & 2.39 & $\begin{array}{c}0.04 \\
\text { (Trivial) } \\
\end{array}$ & & \\
\hline 40-Meter Sprint (s) & & & & & & & & \\
\hline
\end{tabular}




\begin{tabular}{|c|c|c|c|c|c|c|c|c|}
\hline $\begin{array}{c}\text { Week } 1 \\
\text { (season-start) March }\end{array}$ & $6.19 \pm 0.28$ & 5.89 & 6.44 & 5.49 & 6.89 & \multirow{2}{*}{$\begin{array}{c}0.13 \\
\text { (Trivial) }\end{array}$} & \multirow[t]{2}{*}{$5.15 \alpha$} & \multirow{2}{*}{$\begin{array}{c}6.22 \pm 0.26 \\
6.16 \pm 0.05 \\
(-1.0)\end{array}$} \\
\hline $\begin{array}{c}\text { Week } 31 \\
\text { (pre-playoffs) October }\end{array}$ & $\begin{array}{c}6.15 \pm 0.35 \\
(-0.7)\end{array}$ & 5.76 & 6.46 & 5.36 & 7.03 & & & \\
\hline $\begin{array}{c}\text { Week } 53 \\
\text { (season-start) March }\end{array}$ & $\begin{array}{c}6.33 \pm 0.50 \\
(2.3)\end{array}$ & 5.76 & 6.68 & 5.09 & 7.57 & $\begin{array}{c}0.35 \\
(\text { Small })\end{array}$ & & \\
\hline \multicolumn{9}{|l|}{ Bench Press (kg; 1RM) } \\
\hline $\begin{array}{c}\text { Week 1 } \\
\text { (season-start) March }\end{array}$ & $60.7 \pm 12.7$ & 48.0 & 68.0 & 29.1 & 92.2 & \multirow{2}{*}{$\begin{array}{c}1.43 \\
\text { (Large) }\end{array}$} & & $59.1 \pm 12.6$ \\
\hline $\begin{array}{c}\text { Week } 31 \\
\text { (pre-playoffs) October }\end{array}$ & $\begin{array}{c}78.0 \pm 11.5 \\
(28.6)\end{array}$ & 65.0 & 87.0 & 49.3 & 106.6 & & & $\begin{array}{c}56.7 \pm 9.8 \\
(-4.0)\end{array}$ \\
\hline $\begin{array}{c}\text { Week } 53 \\
\text { (season-start) March }\end{array}$ & $\begin{array}{c}80.0 \pm 14.1 \\
(31.9)\end{array}$ & 65.0 & 93.0 & 44.9 & 115.0 & $\begin{array}{c}1.44 \\
(\text { Large })\end{array}$ & & \\
\hline \multicolumn{9}{|l|}{ Bench Pull (kg; 1RM) } \\
\hline $\begin{array}{c}\text { Week 1 } \\
\text { (season-start) March }\end{array}$ & $60.3 \pm 8.32$ & 51.0 & 67.0 & 39.6 & 81.0 & \multirow{2}{*}{$\begin{array}{c}0.21 \\
(\text { Small })\end{array}$} & & \\
\hline $\begin{array}{c}\text { Week } 31 \\
\text { (pre-playoffs) October }\end{array}$ & $\begin{array}{c}58.7 \pm 7.23 \\
(-2.7)\end{array}$ & 54.0 & 67.0 & 40.7 & 76.6 & & & \\
\hline $\begin{array}{c}\text { Week } 53 \\
\text { (season-start) March }\end{array}$ & $\begin{array}{c}63.0 \pm 5.0 \\
(4.4)\end{array}$ & 58.0 & 68.0 & 50.6 & 75.4 & $\begin{array}{c}0.39 \\
(\text { Small })\end{array}$ & & \\
\hline \multicolumn{9}{|l|}{ PDT-Mean (sec) } \\
\hline $\begin{array}{c}\text { Week 1 } \\
\text { (season-start) March }\end{array}$ & $7.57 \pm 0.11$ & 7.45 & 7.65 & 7.31 & 7.84 & \multirow{2}{*}{$\begin{array}{c}2.44 \\
\text { (Large) }\end{array}$} & & \\
\hline $\begin{array}{c}\text { Week 31 } \\
\text { (pre-playoffs) October }\end{array}$ & $\begin{array}{c}6.92 \pm 0.36 \\
(-8.6)\end{array}$ & 6.69 & 7.35 & 6.01 & 8.16 & & & \\
\hline $\begin{array}{c}\text { Week } 53 \\
\text { (season-start) March }\end{array}$ & $\begin{array}{c}7.05 \pm 0.57 \\
(-6.9)\end{array}$ & 6.45 & 7.60 & 5.61 & 8.48 & $\begin{array}{c}1.27 \\
(\text { Large })\end{array}$ & & \\
\hline \multicolumn{9}{|l|}{ PDT-Fatigue (\%) } \\
\hline $\begin{array}{c}\text { Week 1 } \\
\text { (season-start) March }\end{array}$ & $23.4 \pm 5.65$ & 18.3 & 29.5 & 9.37 & 37.5 & \multirow{2}{*}{$\begin{array}{c}1.42 \\
\text { (Large) }\end{array}$} & & \\
\hline $\begin{array}{c}\text { Week } 31 \\
\text { (pre-playoffs) October }\end{array}$ & $\begin{array}{c}15.0 \pm 6.21 \\
(-36.0)\end{array}$ & 8.54 & 20.9 & 1.41 & 30.4 & & & \\
\hline Week 53 & $16.3 \pm 3.77$ & 13.6 & 20.7 & 7.02 & 25.8 & 1.48 & & \\
\hline
\end{tabular}


Rishiraj et al.: Physical and Performance Changes in Rugby Union...

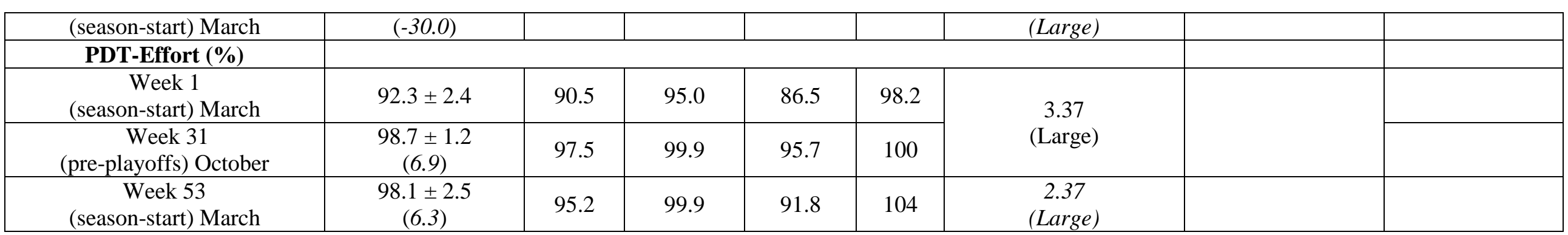

Body mass collected using a calibrated electronic scale (A \& D Engineering Inc.).

*Percent (\%) change over weeks 1 to 31 and weeks 1 to 53.

1RM: One repetition maximum.

RU: Rugby Union.

$\dagger$ Effect size differences between weeks 1 and 31 and weeks 1 and 52(Cohen 1992).

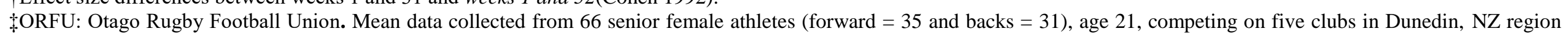
(Quarrie et al. 1995).

aMean performance time for 30-meter sprint(Quarrie et al. 1995).

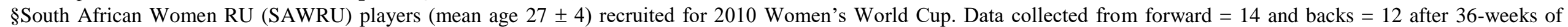
competition, 32-week interprovincial league play and a four week international tour (Hene and Bassett 2013). 


\section{Discussion}

This study is the first to investigate the physical (body weight) and performance (lower-body power, acceleration, speed, upper-body strength, and anaerobic endurance) training adaptations of women student-athletes selected to both the ORFU Academy program and the NZWRU World Cup training squad.

During the competitive season (weeks 1 to 31 ), body weight of the NZWRUSA increased by $1.4 \%$. These data are consistent with a $1.0 \%$ body weight gain by players representing the elite South African Women RU(SAWRU) (Hene and Bassett 2013). However, in comparing the mean (combined forwards and backs) bodyweight of elite SAWRU players (Hene and Bassett, 2013) and ORFU Club Senior Women (Quarrie et al. 1995), the NZWRUSA had higher mean body weight in week 1 (Table 2). At the end of the competitive-season, the NZWRUSA had increased their body weight to $81.9 \pm 19.5 \mathrm{~kg}$, again, higher than the elite SAWRU athletes $(70.7 \pm 8.8 \mathrm{~kg})$. Previous published literature has expressed concern regarding body weight resulting from subcutaneous body fat as being as being "dead weight"/counterproductive and hindering player's work rate and performance (Duthie et al. 2006).

The increase in body weight experienced by the NZWRUSA is also supported by available literature stating that for athletes reaching their adult height, their body weight continues to increase, with simultaneous increase in lean body mass, due to continued resistance training and adequate nutrition (Smart et al. 2013, Till et al. 2014).Although the present study did not collect skin fold data, continued enhancement of all performance variables, except upper body bench pull strength, may suggest a higher level of mesomorphy,a physical characteristic deemed important for elite physiological performance and good tackling ability (Vaz et al. 2015).

Compared to the results from the present study, SAWRU elite players recorded higher lower body power results at the end of their 'competitiveseason'; however, the NZWRUSA attained greater performance improvement (11\%) compared to the $6 \%$ improvement by SAWRU elite players (Hene and Bassett 2013). This increase in lower body power is deemed important as published literature on RL athletes has illustrated the higher lower body power assists with generation of greater leg drive to counter the forward progression of the opposing player during tackling (Gabbett et al. 2007).

The higher lower body power/leg drive generation also allowed the NZWRUSA to accelerate (5 m sprint) at a higher rate, while, both the NZWRUSA and the elite SAWRU athletes had improvements in speed (10 m and 40m sprints) at the end of the irrespective 'competitive season'. These findings are consistent with published literature dating back to 1968, which have illustrated a strong correlation between CMJ/ VJ and sprint speed over various distances (Costill et al. 1968).

A concern may be raised regarding the NZWRUSA having greater body weight and lower body power generation, and still being able to attain faster sprint times over $10 \mathrm{~m}$ and $40 \mathrm{~m}$ distances compared to the elite SAWRU athletes. However, researchers(Cronin and Hansen 2005)have suggested that the power 
to weight ratio plays a crucial role in enhancing sport speed in elite athletes. As such, NZWRUSA must have developed sufficient power output to overcome the increases in body weight, thereby achieving enhancement in acceleration (large ES difference) and speed variables over the 31-week ORFU premier league season. Also, the elite SAWRU authors reported that 'backs' experienced significant increases and 'forwards' had non-significant increases in body weight during the competitive season, which could have contributed to SAWRU athletes' lower percent improvements in the vertical jump and sprint times (Hene and Bassett 2013).

The NZWRUSA recorded a $28.6 \%$ upper body strength gain in the 1RM bench press over the competitive season, but upper body strength bench pull gains decreased by $2.7 \%$ over the same duration. The elite SAWRU athletes experienced a $2.7 \%$ decrease in upper body strength in the 1RM bench press (Hene and Bassett 2013). The lower strength results recorded by both RUs seem to be consistent with published data on male academy RL players who demonstrated only a marginal increase in strength (Till et al. 2014), as well as with Canadian (Schneider et al. 1998) and American (Dos Remedios et al. 1995) collegiate North American Football players who recorded a $8 \%$ and $4 \%$ loss in strength, respectively. Another study on American collegiate North American Football players reported no significant changes in strength(Hoffman and Kang 2003). These small strength changes have been attributed to increased capacity of concurrent aerobic and strength training and/or reduced volume of resistance training, and/or fatigue as a result of overtraining (Hrysomallis 2010). The high percentage of upper body strength gains (1RM bench press) experienced by the NZWRUSA could be attributed several factors:

1. Athletes being introduced to a highly competitive academy training environment (Argus et al. 2012),

2. The increased emphasis on physical enhancement strategies (sport and individual athlete specific training techniques, nutrition, and recovery), and decreased injury risk/rates, which, allow for a cumulative effect of increased strength training capacity/volumes (Gabbett 2005),

3. The competitive, structured, and supervised training environment with continual productive feedback resulted in increased adherence/ compliance from the NZWRUSA thereby allowing for attainment of higher training loads(Argus et al. 2012), and

4. The combined effect of the above mentioned factors could have contributed to enhancing the NZWRUSA 'training age' (duration of training completed), allowing for enhanced movement patterns, increased synchronization of motor units, and decreased concurrent antagonist muscle firing, as well as decreased inhibitory feedback mechanism activation ability (Behm 1995) all leading to the enhancement in anatomical and physiological factors and the production of high levels of force (Argus et al. 2012). 
The NZWRUSA bench press gains, during both the competitive and postcompetitive seasons, are also supported by published data from 14 professional and 15 collegiate male RL athletes (Baker 2001).

The Phosphate Decrement Test (PDT)/repeated sprint test is perceived as being important in evaluating the anaerobic system required for delivering energy during a rugby competition (Duthie et al. 2003), especially, since the intensity of the RU game has increased with the inauguration of the professional Super $12 \mathrm{RU}$ competition (Duthie et al. 2005, Ziv and Lidor 2016). However, there is a lack of anaerobic data on RU players reported in the literature (Duthie et al. 2003).

During the competitive season, PDT-mean NZWRUSA performance improved by $8.6 \%$, along with a $6.9 \%$ enhanced effort (PDT-effort). Performance improvements in these two PDT variables led to the desired decrease in the fatigue rate by $36 \%$; corresponding to higher sustained performance intensity. These results could be a result of an improvement in the anaerobic threshold, specifically, a decrease in a muscle $\mathrm{pH}$, phosphocreatine, ATP activation of anaerobic glycolysis due to a significant involvement of aerobic metabolism (Spencer et al. 2005), and by the enhancement of VO2max and aerobic enzyme activity (MacDougall et al. 1998).

The 17-week unsupervised off-season training duration led to a $3.2 \%$ decrease in bodyweight as well as a decrease in six of the nine performance variables. These findings are consistent with previous literature that have illustrated the importance of supervised versus unsupervised training in RU (Smart and Gill 2013) and RL (Coutts et al. 2004) players. Smart and Gill (2013) attributed the performance enhancement in the supervised RU group to improved adherence and higher training intensity.

Over 52 weeks, body weight decreased by $1.8 \%$ and performance enhancement was noted in all variables, except the $10 \mathrm{~m}$ and $40 \mathrm{~m}$ sprints. These performance improvements are probably attributed to the physiological adaptations detailed above. No published data are available for comparison.

The limitations of this study include the suggestion that weight gain could be a result of higher level of mesomorphy based on enhancement of all but one performance variable and not based on skin fold data. Skin fold data was not collected due to published concerns regarding female athletes physical appearance leading to potentially developing eating disorders (Sundgot-Borgen 1994). Also, subject numbers were limited as data were only collected from female studentathletes selected to the ORFU Academy and the NZRU Black Ferns programs and due to the traumatic injuries experienced by several selected athletes during an international test match.

\section{Conclusions}

The present study provides evidence of performance improvements over the competitive-season and is the first to provide data on physical and performance enhancement over a 31-week competitive season and over 52weeks. These results demonstrate that an increase in body weight, over a competitive season, can still 
lead to performance improvement in lower body power, acceleration $(5 \mathrm{~m})$, speed $(10 \mathrm{~m}$ and $40 \mathrm{~m})$ sprint times, upper body strength (1RM bench press), and anaerobic endurance (PDT-mean, PDT-effort, and PDT-fatigue). Over 52weeks, a decrease in body weight and similar improvements in most of the performance variables were again noted. These findings will allow coaches and strength and conditioning professionals to assist their aspiring RU student-athletes in attaining physical and performance enhancement to compete at the IRB World Cup level.

\section{References}

Anthony M (2003) New Zealand Rugby Union Guidelines for Athlete Assessment in New Zealand Sport - Rugby Union New Zealand (pp. 1-8). Auckland: New Zealand Rugby Union (Inc.).

Argus CK, Gill N, Keogh JWL (2012) Characterization of the differences in strength and power between different levels of competition in rugby union athletes. Journal of Strength and Conditioning Research 26(10): 2698-2704.

Baker D (2001) The effects of an in-season of concurrent training on the maintenance of maximal strength and power in professional and college-aged rugby league football players. Journal of Strength and Conditioning Research 15: 172-177.

Behm DG (1995) Neuromuscular implications and applications of resistance training. Journal of Strength and Conditioning Research 9(1): 264-274.

Bishop D, Edge J (2006) Determinants of repeated-sprint ability in females matched for single-sprint performance. European Journal of Applied Physiology 97(4): 373-379.

Bishop D, Spencer M, Duffield R, Lawrence S (2001) The validity of a repeated sprint ability test. Journal of Science and Medicine in Sport 4(1): 19-29.

Cahill N, Lamb K, Worsfold P, Headey R, Murray S (2013) The movement characteristics of English Premiership rugby union players. Journal of Sports Sciences31: 229-237.

Cohen J (1992) A power primer. Psychological Bulletin 112(1): 155-159.

Costill DL, Miller SJ, Myers WC, Kehoe FM, Hoffman WM (1968) Relationship among selected tests of explosive leg strength and power. Research Quarterly. American Association for Health, Physical Education and Recreation 39: 785-787.

Coutts A, Reaburn P, Piva TJ, Murphy A (2007) Changes in selected biochemical, muscular strength, power, and endurance measures during deliberate overreaching and tapering in rugby league players. International Journal of Sports Medicine 28(2): 116-124.

Coutts AJ, Murphy AJ, Dascombe BJ (2004) Effect of direct supervision of a strength coach on measures of muscular strength and power in young rugby league players. Journal of Strength and Conditioning Research18(2): 316-323. Doi: 10.1519/00124 278-200405000-00021.

Cronin JB, Hansen KT (2005) Strength and power predictors of sports speed. Journal of Strength and Conditioning Research19(2): 349-357.

Dos Remedios KA, Dos Remedios RL, Loy SF, Holland GJ, Vincent WJ, Conely L M,Heng M (1995) Physiological and field test performance changes of community college football players over a season. Journal of Strength and Conditioning Research 9: 211-215.

Duthie G, Pyne D, Hooper S (2003) Applied physiology and game analysis of rugby union. Sports Medicine33(13): 973-991.

Duthie G, Pyne D, Hooper S (2005) Time motion analysis of 2001 and 2002 super 12 rugby. Journal of Sports Sciences 23: 523-530. 
Duthie GM, Pyne DB, Hopkins WG, Livingstone S, Hooper SL (2006) Anthropometry profiles of elite rugby players: quantifying changes in lean mass. British Journal of Sports Medicine40: 202-207. Doi: 10.1136/bjsm.2005.019695.

Gabbett T, Kelly J, Pezet T (2007) Relationship between physical fitness and playing ability in rugby league players. Journal of Strength and Conditioning Research 21(4): 1126-1133.

Gabbett TJ (2005) Physiological and anthropometric characteristics of junior rugby league players over a competitive season. Journal of Strength and Conditioning Research 19: 764-771.

Glaister M, Howatson G, Lockey RS, Abraham CS, Goodwin JE, McInnes G (2007) Familiarization and reliability of multiple sprint running performance indices. Journal of Strength and Conditioning Research 21(3): 857-859.

Hendrick A, Anderson JC (1996) The vertical jump: A review of the literature and team case study. Strength \& Conditioning Journal18(1): 7-12.

Hene NM, Bassett SH (2013) Changes in the physical fitness of elite women's rugby union players over a competition season. South African Journal of Sports Medicine 25(2): 47-50. Doi: 10.7196/SAJSM.371.

Hoffman JR, Kang J (2003) Strength changes during an in-season resistance-training program for football. Journal of Strength and Conditioning Research17: 109-114.

Hrysomallis C (2010) Upper-body strength and power changes during a football season. Journal of Strength and Conditioning Research24(2): 557-559.

MacDougall JD, Hicks AL, MacDonald JR, McKelvie RS, Green HJ, Smith KM (1998) Muscle performance and enzymatic adaptations to sprint interval training. Journal of Applied Physiology 84(6): 2138-2142.

McCurdy K, Langford G, Jenkerson D, Doscher M (2008) The validity and reliability of the 1RM bench press using chain-loaded resistance. Journal of Strength and Conditioning Research22(3): 678-683. Doi: 10.1519/JSC.0b013e31816a6ce0.

Moir G, Button C, Glasister M, Stone MH (2004) Influence of familiarization on the reliability of vertical jump and acceleration sprinting performance in physically active men. Journal of Strength and Conditioning Research18(2): 276-280.

Quarrie KL, Handcock P, Waller AE (1995) The New Zealand rugby injury and performance project. III. Anthropometric and physical performance characteristics of players. British Journal of Sports Medicine 29(4): 263-270.

Schneider V, Arnold B, Martin K, Bell D, Crocker P (1998) Detraining effects in college football players during the competitive season. Journal of Strength and Conditioning Research12: 42-45.

Seo DI, Kim E, Fahs CA, Rossow L, Young K, Ferguson SL, Thiebaud R, Sherk VD, Loenneke JP, Kim D, Lee MK, Choi KH, Bemben DA, Bemben MG, So WY (2012) Reliability of the one-repetition maximum test based on muscle group and gender. Journal of Sports Science and Medicine 11(2): 221-225.

Smart DJ, Gill ND (2013) Effects of an off-season conditioning program on the physical characteristics of adolescent rugby union players. Journal of Strength and Conditioning Research 27(3): 708-713.

Smart DJ, Hopkins GW, Gill DN (2013) Difference and changes in the physical characteristics of professional and amateur Rugby Union players. Journal of Strength and Conditioning Research 27(11): 3033-3044.

Spencer M, Bishop D, Dawson B, Goodman C (2005) Physiological and metabolic responses of repeated-sprint activities: specific to field-based team sports. Sports Medicine 35(12): 1025-1044.

Sundgot-Borgen J (1994) Risk and trigger factors for the development of eating disorders in female elite athletes. Medicine \& Science in Sports \& Exercise 26(4): 414-419. 
Till K, Tester E, Jones B, Emmonds S, Fahey J, Cooke C (2014) Anthropometric and physical characteristics of english academy rugby league players. Journal of Strength and Conditioning Research 28(2): 319-327. Doi: 10.1519/JSC.0b013e3182a73c0e.

Vaz L, Vasilica I, Carreras D, Kraak W, Nakamura FY (2015) Physical fitness profiles of elite under-19 rugby union players. Journal of Sports Medicine and Physical Fitness 56(4): 415-21.

Ziv G, Lidor R (2016) On-field performances of Rugby Union players - A review. Journal of Strength and Conditioning Research30(3): 881-892. Doi: 10.1519/JSC. 0000000000001129. 